\title{
Cuerpos, resistencias y fronteras. Reflexiones desde el feminismo en torno a las políticas de desplazamiento
}

\author{
Bodies, resistances and borders. Reflections from \\ feminism about the displacement policies
}

Andrea Itzel Padilla Mireles

Universidad Iberoamericana andrea.itzelpm@gmail.com

\section{Resumen}

A partir de una revisión desde los feminismos, además de la teoría crítica de las fronteras, este artículo examina el fenómeno de la migración como escenario complejo en el que la articulación cuerpo-territorio puede arrojar luz sobre los movimientos y potencias políticas contemporáneas. Migración, cuerpo y subjetividad son tres conceptos cuya relevancia y 
emergencia en el contexto global apremian la búsqueda, propuesta y experimentación de nuevos marcos analíticos de interpretación.

Palabras clave: fronteras; desplazamientos; feminismos; cuerpo; territorio; política.

\section{Abstract}

Based on a review from feminisms, in addition to the critical theory of borders, this article examines the phenomenon of migration as a complex scenario in which the body-territory articulation can shed light over contemporary political movements and powers. Migration, body and subjectivity are three concepts whose relevance and emergence in the global context urge the search, proposal and experimentation of new analytical frameworks for interpretation.

Key words: borders; displacement; feminisms; body; territory; politics.

\section{Introducción}

Nos encontramos actualmente frente al problema social que probablemente definirá el siglo XXI: la migración. Pero habrá que nombrarla en plural: las migraciones. Este plural es necesario y responde a las múltiples formas y tipos en los que estas han ido sucediendo y proliferando. Lo que podemos establecer como marco común es el traslado de cuerpos, y con esto sumaríamos el traslado de subjetividades. Esto pone aún más tensión respecto a este problema y nos 
lleva inmediatamente a otro factor que ha definido la migración en la actualidad: el Estado moderno, lo que éste ha establecido como fronteras y con ello todos sus derivados implicados, desde la ciudadanía hasta los derechos humanos. La emergencia y complejidad de este problema (en las de coyunturas género, raza y clase) y sus múltiples causas (cambio climático, guerras civiles, crimen organizado, violencia, extractivismo, etc.), nos demanda la generación y la propuesta de nuevos y más amplios marcos teóricos de interpretación que puedan atender los rápidos procesos que están marcando las dinámicas locales, globales (glocales, si se prefiere) que se experimentan como cada vez más graves y urgentes.

El presente trabajo representa una primera aproximación a este fenómeno en su articulación con otro de los problemas vinculado a las migraciones y los desplazamientos: el género y la subjetividad, cuyo espacio de ensamblaje tiene de manera irrevocable al cuerpo. Esta aproximación se realiza a partir del análisis de las teorías feministas y las teorías de las fronteras; supone, principalmente, una serie de esbozos que intentan problematizar las formas en las que se entienden (teórica y metodológicamente) las migraciones, las fronteras, el cuerpo y la subjetividad dentro de este contexto global complejo. En un primer momento trataremos de contextualizar esta compleja articulación y la manera en que ha sido abordada para, en un segundo momento, introducir las teorías 
feministas y las teorías contemporáneas de las fronteras, a partir de su aporte en relación con esta problemática. Así en un tercer momento abordaremos la relación cuerpo, resistencia y fronteras desde las posibilidades que nos otorgan estos dos enfoques, para apuntar la posibilidad de entender los desplazamientos y las fronteras desde un planteamiento que contemple los flujos de poder y el movimiento más allá de sus implicaciones solo físicas o geopolíticas.

Este ejercicio está enmarcado en un interés más amplio de una investigación doctoral, por lo cual, lo que ahora se presenta en este texto debe ser entendido como un marco de cuestionamientos que intentan proponer una posible hermenéutica de los desplazamientos y del devenir de los cuerpos y las subjetividades; que, además, atienda a la emergencia en la que nos encontramos a partir de la revisión de las propuestas contemporáneas de los feminismos y la teoría de las fronteras. Por esa razón, nuestro último apartado representa la suma de los cuestionamientos y preguntas emanadas de este ejercicio, que pretenden ser parte sustancial de la investigación que se lleva a cabo actualmente y que apunta a poder desarrollar las complejas relaciones que recién empiezan a señalarse en este ensayo. 


\section{Las emergencias globales de las migraciones}

Las migraciones se materializan como fenómeno cuya presencia recurrente en la historia de la humanidad se insiste con fuerza, determinando dinámicas que han impactado de diferentes maneras en diferentes lugares del globo ${ }^{1}$; por esto, es necesario especificar que si bien los distintos movimientos de migraciones han suscitado el seguimiento mediático, otorgándoles una gran visibilidad desde principio de siglo, no podemos pensarlos solo como resultado de este momento histórico y de las actuales dinámicas de la globalización, sino a partir de la articulación con los procesos de la misma (Sassen, 2007) y de su mutación. Por lo que es necesario interrogarse qué distingue a las migraciones de nuestro tiempo en su forma indisociable con los procesos globalizantes. Atendiendo al hecho de que este «nuestro tiempo» representa un complejo escenario cuyas interconexiones y convivencias no pueden analizarse de manera separada.

Por lo anterior, es necesario advertir la emergencia de estas migraciones aunada a la vuelta del reforzamiento de las fronteras, y con esto, la vuelta de los reforzamientos de los nacionalismos y los fundamentalismos. ¿Qué rastros son los

${ }^{1}$ Véase Bacci, Massimo Livi (2012) Breve historia de las migraciones, Madrid: Alianza. 
que nos permiten ir hilando tal relación? Para poder entender cómo se están imbricando estos vínculos podemos partir del desbordamiento del Estado moderno y de su evolución a partir de la administración biopolítica de los cuerpos y los flujos de poder en la globalización. Es desde estos procesos acelerados de incertidumbre en varias esferas (política, social y económica) que el emblema de las naciones se encuentra rebasada por la propia aceleración de las dinámicas sociales, mediáticas, tecnológicas y de mercado.

En coincidencia casi profética vuelve aquella observación de Marx en la que la mercancía detenta toda libertad de tránsito (Marx, 1980) mientras que las personas son retenidas física y simbólicamente, una reflexión que podemos continuar con Hannah Arendt quien anota cómo frente al problema del éxodo provocado a partir de la primera guerra mundial en Europa, las personas que eran desplazadas por las múltiples situaciones brotadas de este conflicto se convertían en la «la escoria de la Tierra» (Arendt, 1998: 225). Esto último puede traerse a nuestros días y recalcar: quien se encuentre desplazado, esto es, desplazándose sin pasaporte, parece encontrarse desprovisto de subjetividad, simplificando, no somos nadie sin documentos que nos identifiquen como ciudadanos de un Estado-nación.

Así, las libertades económicas no son las mismas para los cuerpos-subjetividades habitantes de los diferentes territorios del globo. Saskia Sassen introduce esta 
observación: «La globalización socioeconómica desnacionaliza la economía nacional. En cambio, la inmigración renacionaliza la política», y continúa: «el estado reclama todo su antiguo esplendor afirmando su derecho soberano a controlar sus fronteras» (2001: 73). Podemos, desde aquí, subrayar la continuidad del Estado moderno ya no en su poderío (potestad) en términos de economía ni territorio, sino en el sostenimiento de su poder en los cuerpos y los espacios (relación indisociable): los cuerpos se convierten en el territorio. Se refuerza el control de las fronteras y así se refuerza el control de los cuerpos, una coreografía de flujos de poder se abre en esta relación, la frontera no puede sostenerse sin los cuerpos, y los cuerpos parecen encarnar la frontera misma.

En diálogo con Sassen, Wendy Brown señala un significativo vínculo en la relación entre el Estado-nación, soberanía, fronteras y sus reforzamientos, en el que podemos encontrar a este como política de desplazamiento, añadiendo el reforzamiento de las fronteras e identidades nacionales como escultores de los cuerpos-subjetividades, el discurso simbólico los imaginarios sobre estos:

La contención dentro de un mundo con cada vez menos fronteras es una especie de anhelo psíquico que alienta el deseo de construir muros; la fantasía de impermeabilidad - tal vez incluso impenetrabilidadlo complementa. El poder soberano alimenta la 
fantasía de una distinción absoluta y factible entre interior y exterior. Esta distinción, a su vez, depende del desafío que plantean a la soberanía la porosidad y la interrupción temporal o la ambigüedad del territorio de las fronteras, la soberanía política, como la de Dios, implica control jurisdiccional absoluto y permanencia a lo largo del tiempo [...] Al respecto, la soberanía se presenta como una fantasía (o una falacia) política extremadamente masculina de dominación. La penetración, la pluralización o la interrupción suponen su destrucción literal (Brown 2015: 174).

Brown anota aquí el impacto del nexo globalizante de dependencia de los Estados-nación, que se expresa a manera de paradoja, por un lado, en la disolvencia de las fronteras como delimitación de los territorios $\mathrm{y}$, por otro, en el obstinado control de los cuerpos-subjetividades. Este traslado (de territorio a cuerpo-subjetividad) posibilita la vuelta a la añoranza de «la identidad» a través la construcción de muros y bordes que intentan dar cierta solidez tanto a las naciones y como a sus ciudadanos. Este levantamiento de muros se expresa como acto de autoridad masculina patriarcal del Estado (pater familias, soberano de todo cuanto ocupa el territorio nacional) como gobernador que decreta los límites de los cuerpos, los territorios y las subjetividades.

Pero bajo este reforzamiento no solo encontramos los poderes estatales vinculados a los patriarcales sino también 
la colaboración de éstos con otros que marcan la interdependencia global en términos de capital, estableciendo lo que Rita Segato ha denominado «frente colonial-estatal-empresarial-mediático-cristiano» (Segato, 2016: 91). Resalta así la vinculación de otros grandes flujos de poder global: el comunicativo, el religioso y epistémico (particularmente en Occidente y Latinoamérica).

Entonces, de qué manera podemos proponer líneas posibles para marcos de análisis y observación a la multiplicación y diversificación del fenómeno migratorio, el cual ha sido definido constantemente como hecho oscilante entre dos categorías condicionantes de la modernidad ${ }^{2}$ : el Estado y la ciudadanía. A partir de la observación de Thomas Nail, podemos distinguir cómo la figura del migrante ha funcionado siempre de manera predicativa, a saber, siempre dicho en relación ya sea con un lugar de origen (emigrante) o con el lugar de llegada (inmigrante), diseminando su propia subjetividad-cuerpo en devenir (Neil, 2015: 24), precisamente por desbordar los marcos que definen su propia entidad. En este sentido es que el devenir mismo del cuerpo-territorio-subjetividad se cristaliza en sí mismo como un problema a abordar y analizar.

2 Entendiendo por ésta, tanto modelo epistémico y diferentes momentos históricos que podríamos ubicar desde la conquista y colonia de América, hasta la revolución francesa e industrial. Véase Berman, Marshall. (1989). Todo lo sólido se desvanece en el aire. México: Siglo XXI. 
Feminismo(s) y teoría crítica de las fronteras

Queremos ahora introducir la posibilidad de análisis y revisión crítica de los feminismos para repensar el problema de las migraciones, las fronteras y el cuerpo-subjetividad, con la precisión de entender la riqueza y aportación que desde hace tiempo elaboran los feminismos sobre estos temas, traerlos a la discusión en este ensayo es no solo reiterar su posibilidad como propuesta epistemológica sino además su pertinencia política.

El feminismo puede ser entendido en un gran espectro de campos, tanto como movimientos sociales y políticos heterogéneos, como teoría o estudios interdisciplinarios que observan las relaciones de género. Aquí consideramos necesario plantearlo como paradigma crítico de conocimiento. Lo que no debe entenderse, a la forma de la propuesta de Kuhn, como modelo que se consuma en el tiempo, sino más bien desde su uso en la lingüística, como «conjunto de unidades» que pueden sustituir a otras para realizar una función en un determinado contexto. Este ejercicio supone una sustitución que logra una sospecha crítica capaz de 
desplazar al falogocentrismo ${ }^{3}$, que se impone como lógica de exclusión que discrimina toda forma de conocimiento otro (Braidotti, 2002). El falogos detenta la autoridad sobre el conocimiento y la palabra a partir del poder fálico, entender su prevalencia en la historia del conocimiento debe entenderse a partir de la centralidad incuestionable del pensamiento occidental, que funciona como normatividad política, cognitiva y moral. Así, el feminismo ha operado como desplazamiento de la lógica falogoéntrica articulando varios ejes a favor de afirmar la experiencia y materialidad de los cuerpos-subjetividades en devenir, mermando este poder epistemológico centralista en la intención de conocimientos otros, encarnados y situados (Haraway, 1995).

En este seguimiento, ha sido fundamental para los feminismos partir de la diferencia y la multiplicidad que considera el devenir de los cuerpos-subjetividades en función de desplazar las lógicas patriarcales y falogocéntricas de poder, lo que ha concretado en distintos momentos históricos en su quehacer político colectivo (en donde nacen los feminismos) cuestionado y problematizado los flujos de poder que les atraviesa, conociéndose y experimentando el devenir mismo como posibilidad de acción y transformación política. Esto debe leerse como un constante diálogo que ha construido puentes desde distintos lugares, cosmovisiones y

3 Término introducido por Jacques Derrida en La farmacia de Platón, pero trabajado de manera más amplia en Metamorfosis de Rossi Braidotti. 
experiencias que resisten estas lógicas patriarcales/coloniales de poder.

Por lo anterior, consideramos que no es casualidad encontrar las propuestas epistemológicas y políticas feministas esbozando el devenir político y cognitivo de fenómenos como la migración, los desplazamientos y la globalización en convivencia con la propuesta de la teoría contemporánea de las fronteras; esta, como dimensión reinterpretativa de los límites, cuya crítica intenta separarse de las lógicas hegemónicas que suponen los límites físicos o geopolíticos, para observar cómo lo simbólico y lo material se encuentran interrelacionados en el devenir de los cuerpossubjetividades-territorios, es decir, otro intento más por desplazar los marcos impuestos por el falogos moderno/occidental. Estos trabajos en ningún momento suponen un mismo un proyecto intelectual homogéneo, más bien destacan por su diversidad y heterodoxia al momento de abordar tales temáticas, tal es el caso de Gloria Anzaldúa, Rosi Braidotti, Elizabeth Groz, Chiara Brambillia, cuyo cruce entre los materialismos, posthumanismos, estudios de la frontera y feminismos serán fundamentales para proponer nuevos marcos conceptuales ante las problemáticas globales.

Desde lo anterior, se considera entonces la necesidad de extender, ajustar y experimentar con los marcos interpretativos que hasta ahora nos han definido la figura del migrante. Para plantearla ahora como cuerpo-subjetividadterritorio en devenir, utilizando una aproximación crítica y 
situada, que hable del movimiento a partir del cruce y articulación de los múltiples flujos de poder que le atraviesan. De aquí que surja la pregunta por ¿qué marcos serán necesarios en el análisis de tales flujos? Las líneas que siguen intentan buscar un posible acercamiento desde la propuesta conceptual de los feminismos contemporáneos y la teoría crítica de las fronteras hacia el debate del evento específico que significó la irrupción de Caravana Migrante Centroamericana en octubre del año 2018.

\section{Cuerpos, resistencias y fronteras}

A partir de octubre del $2018^{4}$ el mundo advirtió y acompañó, ya sea a través de los medios de comunicación o como experiencia inmediata, el masivo desplazamiento de migrantes (cuerpos-subjetividades-territorios) de la Caravana Migrante Centroamericana, que entró súbitamente a un complejo contexto político tanto en EE.UU. como en México y sus relaciones comerciales y diplomáticas (como el paso del TLCAN a el USMCA), esto aunado al anunciado

${ }^{4}$ Para la cronología completa de los sucesos que marcaron el desplazamiento de la Caravana Migrante véase el informe completo Observatorio de legislación y política migratoria realizado por El Colegio de la Frontera Norte con apoyo de la Comisión Nacional de los Derechos Humanos. Disponible en http://observatoriocolef.org/infograficos/cronologia-de-la-caravanacentroamericana 
muro fronterizo prometido en la campaña del ahora presidente de EE. UU., Donald Trump. A pesar del largo historial de migración latinoamericana, especialmente la centroamericana y mexicana, esta masiva movilización se distinguió de las anteriores formas migratorias. Algunos rasgos que la distinguieron son: el desplazamiento masivo en grupo, lo que le dio el nombre de «caravana»; la gran visibilización mediática a escala global, además de las múltiples respuestas, ya sea del Estado tanto mexicano como estadounidense, así como de los pobladores que en algunos casos atendieron a la población migrante $\mathrm{y}$ en otros agredieron y rechazaron a la misma.

Un primer momento de análisis nos hace introducir la observación de Judith Butler en relación al término vulnerabilidad, una acepción de este precariousnees debe entenderse como condición ontológica, mientras que precarity tendría la connotación de una inducción social sostenida en el neoliberalismo global (Butler, 2009), de aquí, encontramos distintas formas de «vulnerabilidad» conviviendo e incrementándose en las complejas dinámicas sociales. Al reconocer una distinción entre estas, hay que plantearse de igual modo, ¿cómo es que conviven y se entienden dos formas que generan dinámicas sociales que se reorganizan en función de los miedos y ansiedades de las personas?, añádase a ello la esperanza y la empatía, como afectos cuya fuente y materialidad debe pensarse ahora no solo en su aspecto psicológico, sino también en un sentido 
político, esta experiencia, además, no sucede solamente a un nivel individual sino también de manera colectiva. Un ejemplo puede ser la problemática reacción de los vecinos de Playas de Tijuana a las primeras llegadas de la caravana centroamericana el 14 de noviembre del 20185: en una respuesta violenta con palos y piedras exigían, mientras cantaban el himno nacional mexicano, el regreso de los migrantes a sus países de origen. Aquí se levanta un muro, el que se erigió frente a la caravana, pero no el prometido por Trump, sino el de los ciudadanos tijuanenses exigiendo su presencia fuera del país.

De esta manera, las fronteras se complican, sus límites dejan de ser reconocidos en función de las dinámicas geopolíticas, se disputan ahora como zona de indefinición donde se materializan los bordes a partir de las dinámicas de los afectos, los imaginarios y las condiciones de riesgo experimentadas por los cuerpos-subjetividades-territorios. Así, la frontera como espacio donde los desplazamientos se materializan, se funden y se vuelven a esbozar, sucede también como reforzamiento de la política de exclusión, que encuentra su narrativa hegemónica en los fundamentalismos y nacionalismos, articulando de esta manera políticas corporales de exclusión y marginalización. De nuevo en la observación de Rita Segato:

5 Véase: https://www.excelsior.com.mx/nacional/vecinos-rechazan-a-migrantescomunidad-de-playas-tijuana/1278800 
La red de los cuerpos pasa a ser territorios, y la territorialidad pasa a ser una territorialidad de rebaño en expansión dado por los cuerpos. Como nunca antes, por esta soltura de las redes con relación a la jurisdicción territorial estatal-nacional, con sus rituales, códigos e insignias, la jurisdicción es el propio cuerpo, sobre el cuerpo y en el cuerpo que debe ahora ser el bastidor en que se exhiben las marcas de la pertenencia (Segato, 2016: 67).

A partir de aquí podemos observar la coyuntura territorio-cuerpo-subjetividad como devenir fronterizo, razón a la cuál atiende nuestra búsqueda por marcos que nos ayuden a abordar el desplazamiento y la movilidad desde su condición fronteriza. Así, frontera ya no puede solo sostenerse en la relación Estado-nación-ciudadanía, ni puede sujetarse en los confines de «punto de llegada» o "punto de salida», no obstante, no se puede perder de vista que su devenir sigue transcurriendo en flujos de poder, en los que las hegemonías (heteronorma, patriarcado, colonialismo) se imponen en el control del cuerpo-territorio como forma de autoridad y soberanía estatal.

Lo que se tiene que subrayar ahora es la materialidad en devenir de los afectos y emociones, que se convierte también en lucha y apuesta política. Aparecen al centro del debate como potenciales reconductores de los flujos de poder hacia la autonomía y el reclamo por lo que Lorena Cabnal llama el «territorio-cuerpo» posibilitando, a su vez, la 
autonomía del «territorio-tierra» (Cabnal, 2010), tal como el feminismo comunitario ha señalado en su resistencia desde los afectos-cuerpos-subjetividades-territorios apuntando la dimensión política que tiene que ser reclamada desde la materialidad de los cuerpos otros. En este seguimiento de ideas, se vuelve necesaria la problematización de los límites entre lo que es y lo que no es, así como los orígenes y destinos en una relación antitética de opuestos excluyentes, para ahora hacer énfasis en el devenir de la interdependencia, pero ahora en su posibilidad política de resistencia desde los cuerpos-subjetividades-territorios y no en la de la economía neoliberal global.

Siguiendo a Rosi Braidotti (quien a su vez sigue a Negri y a Hardt) podemos observar en el cuerpo-subjetividadterritorio el encuentro de dos fuerzas de poder, aquella que se puede denominar potestas, que se presenta como ejercicio impositivo que delimita y coacciona, podríamos decir de arriba hacia abajo; pero también, se ubica la potentia, que empuja, capacita y potencializa al cuerpo como insistencia y resistencia (Braidotti, 2002). Aquí señalaríamos que esta potencia no solo fluye de abajo hacia arriba, sino también en múltiples direcciones transversales, que es precisamente donde se afirma su potencia. El cruce de estos flujos no puede sino reiterarnos las formas en las que la caravana ha implicado una redefinición de movimiento social y resistencia política, cuya potencia no puede ser demarcada y 
cuyo avance, ya no solo cinético sino también simbólico, aún no puede ser conmensurable.

Pero, en este escrutinio conceptual no solo la relación poder-cuerpo-territorio debe ser revisada, sino también el concepto mismo frontera, entendida solo como borde sobre el cual chocan los flujos y devenires. Frontera, en esta reelaboración, se encuentra fundiéndose con el mismo devenir cuerpo-territorio-subjetividad, aquí el concepto Chiara Brambillia (2015) de borderscapes como «paisajes fronterizos», posibilita lo fronterizo como discusión e interpretación política renovada sobre «quiénes somos» y «hasta dónde llegamos» en las dinámicas y flujos de poder acaeciendo en la insaciable vorágine del neoliberalismo, el colonialismo y el heteropatriarcado en su forma global. Retomando a Perera, Brambilla señala que:

[...] borderscapes is linked to the urgency to find a new concept that can express the spatial and conceptual complexity of the border as a space that is not static but fluid and shifting; established and at the same time continuosly traversed by a number of bodies, discourses, practices and relationships that higlight endless definitions and shifts in definitions between inside and outside, citizens and foreigners, hosts and guests across state, regional, racial, and other symbolic boundaries (Brambillia, 2015: 19). 
Es así que encontramos la materialidad de los cuerpossubjetividades-territorios atravesada a su vez por distintos flujos de poder, pero en esta interrelacionalidad se posibilita el reconocernos como articulaciones en devenir, cuyo desplazamiento funciona a manera de conductos que trasladan esos flujos desde donde nuevos encauces empujan y desplazan los «paisajes fronterizos» hacia la rearticulación de las lógicas hegemónicas imperantes.

\section{Desplazamientos simbólicos}

Recogemos ahora algunos de los puntos trabajados como ejes-preguntas para reflexionar. Introducir la revisión y complejización del cuerpo-frontera-territorio-subjetividad tiene la intención de destacar no solo los desplazamientos físicos, sino también los simbólicos, es decir, dar cuenta de los cruces de flujos de poder desde la profundidad del lenguaje, los imaginarios, los afectos y las representaciones así como el ejercicio jerárquico de la distribución y categorización de la vida social, sin dejar de lado el aspecto material de las subjetividades, de las prácticas y los espacios de poder. No obstante verlos separados como entidades excluyentes parece detener el análisis a categorías ficcionales que refuerzan las ideas de estabilidad a la forma de Estadonación y ciudadanía, estas categorías como revisamos a lo largo de este ejercicio no puede sino verse mermadas por los mismos procesos de aceleración global y de interdependencia en los escenarios sociales actuales. 
Para concluir este ejercicio, que debe tomarse como provocación, ensayo-laboratorio de cuestionamientos conceptuales hacia marcos más amplios, móviles y a la vez más precisos de las fronteras y las migraciones, nos gustaría señalar algunas ideas finales. En principio los desplazamientos tienen que ser entendidos como inacabados, siempre en devenir y nunca como conclusión de un procedimiento definido en relación a su «punto de partida» y su «punto de llegada». Los desplazamientos no concluyen en el arribo de los cuerpos-territoriossubjetividades (entendiendo este como espacio o como identidad), estos ensamblajes se expresan como movimiento constante y es desde aquí que surge se potencial político. En este tejido de ideas la aportación de los feminismos nos apunta no solo el potencial político de la diferencia encarnada en los cuerpos otros, sino también la constante crítica en el devenir de la resistencia de lo que Rita Segato llama «frente colonial-estatal-empresarial-mediáticocristiano», así como la constante necesidad de trabajar los conceptos desde las experiencias y conocimientos situados de los cuerpos-subjetividades-territorios.

De ahí que los desplazamientos nunca sucedan de forma neutral o abstracta y que siempre tengan que ser analizados en su diferencia, multiplicidad y cotidianidad, pues solo desde ahí es donde encontrará su posible resistencia y rencauce de las políticas de desplazamiento. Esto último también refirma el potencial mismo de los 
feminismos como plataforma crítica onto-epistémico-política para observar, analizar e interpretar los fenómenos emergentes del presente glocal, así como las convergencias y alianzas hacia prácticas deconstructivas o de la diferencia, decoloniales y comunitarias, que entiendan y vivan la política en el empuje de los cuerpos-territoriossubjetividades y en el potencial de la reconducción de los flujos de poder.

\section{Bibliografía}

Arendt, H. (1998). Los orígenes del totalitarismo, trad. Guillermo Solana (trad.). Madrid: Taurus.

Berman, M. (1989). Todo lo sólido se desvanece en el aire, Andrea Morales Vidal (trad.). México: Siglo XXI.

Braidotti, R. (2002). Metamorfosis. Hacia una teoría materialista del devenir, Ana Varela Mateos (trad.). Madrid: Akal.

Brambilla, C. (2015). Exploring the Critical Potential of the Borderscapes Concept. New York: Routledge.

Brown, W. (2015). Estados amurallados, soberanía en declive, Antonio Martínez-Riu (trad.). Barcelona: Herder.

Butler, J. (2009). Performatividad, precariedad y políticas sexuales. Revista de antropología iberoamericana. No. 3, Vol.4. pp. 321-336. 
Cabnal, L. (2010). Feminismos diversos. El feminismo comunitario. Madrid: ACSUR-Las segovias

Haraway, D. (1995). Ciencia, cyborgs y mujeres. La reinvención de la naturaleza, Manuel Talens (trad.). Madrid: Cátedra. Marx, K. (1980). Manuscritos: economía y filosofía, Francisco Rubio Llorente (trad.). Madrid: Alianza.

Neil, T. (2015). The figure of the migrant. California: Standford University Press.

Sassen, S. (2007). Una sociología de la globalización, María Victoria Rodil (trad.). Buenos Aires: Akal.

Sassen, S. (2001). ¿Perdiendo el control? La soberanía en la era de la globalización, Víctor Pozanco (trad.). Barcelona: Bellaterra.

Segato, R. L. (2016). La guerra contra las mujeres. Barcelona: Traficantes de sueños. 